\title{
Interstitial nephritis caused by HIV infection by itself: a case report
}

\author{
This article was published in the following Dove Press journal: \\ International Journal of General Medicine \\ I September 2016 \\ Number of times this article has been viewed
}

\author{
Asako Doi ${ }^{1,2}$ \\ Kentaro Iwata ${ }^{3}$ \\ Shigeo $\mathrm{Hara}^{4}$ \\ Yukihiro Imai $^{5}$ \\ Toshikazu Hasuike ${ }^{1,2}$ \\ Hiroaki Nishioka ${ }^{1,2}$ \\ 'Department of Infectious Diseases, \\ 2Department of General Internal \\ Medicine, Kobe City Medical Center \\ General Hospital, ${ }^{3}$ Division of \\ Infectious Diseases, ${ }^{4}$ Department of \\ Diagnostic Pathology, Kobe University \\ Hospital, ${ }^{5}$ Department of Pathology, \\ Kobe City Medical Center General \\ Hospital, Kobe, Hyogo, Japan
}

\begin{abstract}
Interstitial nephritis is a common cause of renal dysfunction. It is primarily caused by drugs, infections, or autoimmune disorders. Patients with human immunodeficiency virus (HIV) infection can develop interstitial nephritis, although it typically occurs because of the aforementioned etiologies and not as a direct consequence of HIV infection. Interstitial lesions may occur in patients with HIV-associated nephropathy (HIVAN). However, interstitial nephritis without the glomerular injuries characteristic of HIVAN, and without the risk factors described earlier, is very rare. Here, we describe a rare case of interstitial nephritis that was likely caused directly by HIV infection and not by other etiologies.
\end{abstract}

Keywords: human immunodeficiency virus, interstitial nephritis, HIV-associated nephropathy

\section{Introduction}

Kidney diseases are common in HIV-infected patients. ${ }^{1-7}$ The most common one is HIVassociated nephropathy (HIVAN), as well as drug toxicities of various kinds. Interstitial nephritis is a possible complication of HIV infection. ${ }^{8,9}$ It is usually caused by drugs such as indinavir, foscarnet, abacavir, and co-trimoxazole; mycobacterial infections; infections by other viruses; or dysimmune syndromes such as immune reconstitution inflammatory syndrome and diffuse infiltrative lymphocytosis syndrome (DILS; Table 1). ${ }^{10,11}$ Interstitial nephritis might occur as a direct consequence of HIV infection, but cases demonstrating this through exclusion of other etiologies are rare. Herein, we present a case of interstitial nephritis that was likely caused directly by HIV infection and not by other etiologies.

\section{Case report}

A 34-year-old African man was referred to our hospital because of microscopic hematuria identified at an annual health checkup at his workplace. The patient had no significant past medical history and was not taking any medications. The patient gave written informed consent to be included in this case report.

Upon initial routine workup, the patient's HIV test was positive. Subsequent blood tests showed CD4 count was 139 cells $/ \mu \mathrm{L}$ and viral load was $5.1 \times 10^{4} / \mathrm{mm}^{3}$. The patient's serum creatinine level was $0.86 \mathrm{mg} / \mathrm{dL}$, with blood urea nitrogen of $10.1 \mathrm{mg}$ / dL. Urinalysis showed red blood cell (RBC) 3+ and urinary sediment showed dysmorphic RBCs (>100/high power field) with RBC casts and absence of white blood cells. Urine $\beta 2$-microglobulin was $913 \mu \mathrm{g} / \mathrm{L}$, urine $N$-acetyl-beta-D-glucosaminidase was 14.9 U/L, and urine protein was $0.217 \mathrm{~g} / \mathrm{d}$. The patient was subsequently diagnosed
Correspondence: Kentaro Iwata Division of Infectious Diseases, Kobe University Hospital, Kusunokicho 7-5-2, Chuoku, Kobe, Hyogo 650-0017, Japan Tel +81783826296 Fax +81783826298 Email kentaroiwata1969@gmail.com 
Table I Common etiologies of interstitial nephritis among HIV-infected patients ${ }^{10,11}$

\begin{tabular}{ll}
\hline Etiology & Characteristics \\
\hline Drugs & Hypersensitivity reactions caused by drugs, including indinavir, abacavir, atazanavir, foscarnet, trimethoprim/ \\
& sulfamethoxazole, and NSAIDs \\
Infections & TB, nontuberculous mycobacteria such as MAC, and viral infections such as EBV and CMV \\
DILS & Seen in poorly controlled patients after long periods of ART. CD8 ${ }^{+}$T lymphocyte infiltration is seen in various \\
& visceral organs, particularly in the bilateral lacrimal and salivary glands \\
IRIS & Usually occurs soon after initiation of ART. Diffuse infiltration of CD4 ${ }^{+}$T lymphocytes may be seen \\
HIVAN ${ }^{2, I I}$ & A type of FSGN, which is typically accompanied by proteinuria and impairment of renal function. Continuous \\
& lesions in both glomeruli and tubules are usually observed
\end{tabular}

Abbreviations: HIV, human immunodeficiency virus; NSAIDS, nonsteroidal anti-inflammatory drugs; TB, tuberculosis; MAC, Mycobacterium avium complex; EBV, EpsteinBarr virus; CMV, cytomegalovirus; DILS, diffuse infiltrative lymphocytosis syndrome; ART, antiretroviral therapy; IRIS, immune reconstitution inflammatory syndrome; HIVAN, HIV-associated nephropathy; FSGN, focal sclerosing glomerulonephritis.

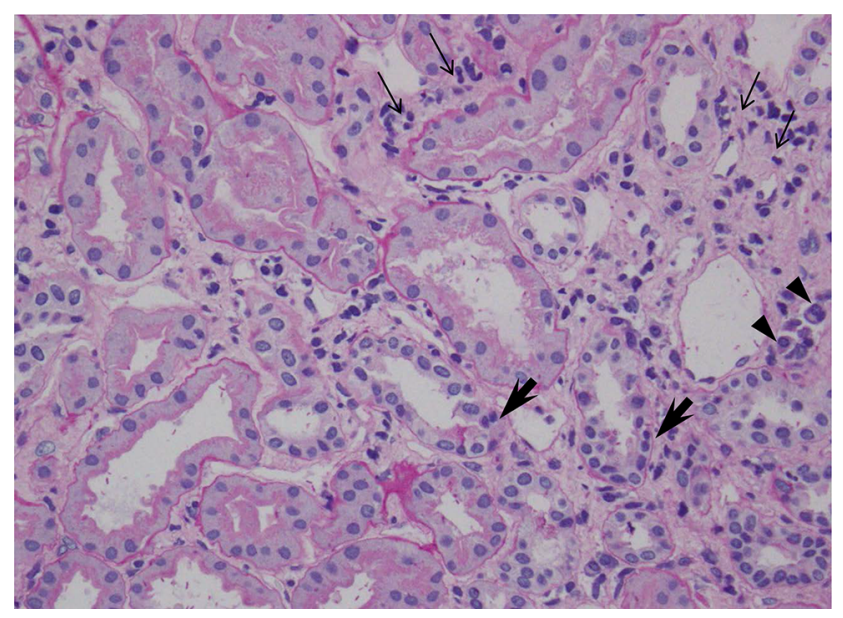

Figure I Histopathology of kidney biopsy specimen shows focal interstitial infiltration of lymphocytes (small arrows) and plasma cells (arrow heads) in the renal cortex as well as in the corticomedullary junction, along with the mild tubulitis with infiltrating lymphocytes (large arrows; PAS, $\times 200$ ).

Abbreviation: PAS, periodic acid-Schiff.

with pulmonary tuberculosis and was treated with a standard regimen including four drugs for 2 months, followed by isoniazid and rifampin for 4 months.

Because of persistent hematuria, the patient was hospitalized to undergo renal biopsy. The histopathological analysis revealed focal interstitial infiltration of lymphocytes and plasma cells in the renal cortex as well as in the corticomedullary junction, accompanied by mild tubulitis without microcysts (Figure 1). No tubular necrosis was observed, with erythrocytic casts and flattened tubular epithelium (Figure 2). Analysis of glomeruli showed no evidence of podocyte hypertrophy, glomerular collapse, or endocapillary hypercellularity (Figure 2). These findings were consistent with the diagnosis of focal and mild tubulointerstitial nephritis. Ziehl-Neelsen staining of the biopsied specimens was negative, and there were no pathological findings suggestive of tuberculosis.

Two weeks after the initiation of treatment for tuberculosis, antiretroviral therapy (ART), including lamivudine, aba-

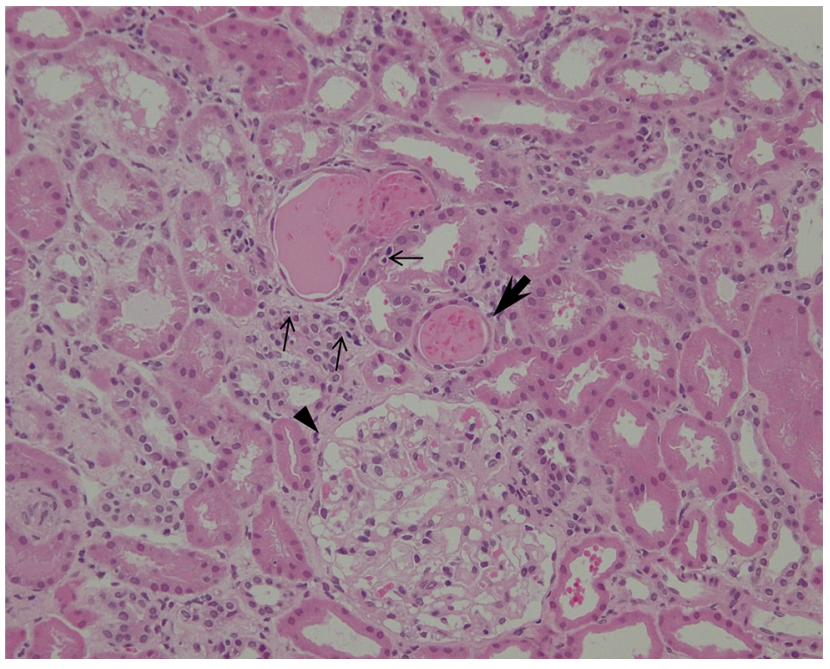

Figure 2 Microscopic view of the renal cortex showing intraepithelial lymphocyte infiltration (small arrows), erythrocytic cast with flattened tubular epithelium (large arrow), and normal glomerulus (arrow head; H\&E, $\times 200$ ).

Abbreviation: H\&E, hematoxylin and eosin.

cavir, and dolutegravir, was started. The 6-month treatment for tuberculosis was completed successfully. Eight months after the initiation of ART, urinary levels of $\beta 2$-microglobulin and $N$-acetyl-beta-D-glucosaminidase normalized and microscopic hematuria resolved completely.

\section{Discussion}

The present report describes an HIV-infected patient with pathologically confirmed interstitial nephritis. The onset and diagnosis of interstitial nephritis occurred prior to initiation of ART or any other medications, eliminating the possibility of it being drug induced. Inflammatory disorders such as immune reconstitution inflammatory syndrome and DILS could not have been the cause of interstitial nephritis in the present case because ART was started only after the onset of renal disease. Additionally, there were no manifestations characteristic of DILS such as parotid gland enlargement. Moreover, other infections were unlikely to be causes of interstitial nephritis, 
as there were no signs of infectious diseases other than HIV and tuberculosis. Finally, pathological findings were inconsistent with tuberculosis as the cause of interstitial nephritis.

HIVAN is the most common cause of renal dysfunction in patients with HIV, and only up to $10 \%$ of renal dysfunction is caused by interstitial nephritis., ${ }^{4,5}$ HIVAN is characterized by proteinuria, with histopathological changes such as focal and segmental glomerulosclerosis or collapsing or noncollapsing nephropathy. Clinical diagnosis of HIVAN is frequently made intuitively and without the need for biopsy. However, diagnostic confirmation by kidney biopsy is often important, particularly when the typical proteinuria is not observed, and other diagnoses such as those related to diabetes or hypertension can be confirmed frequently by kidney biopsy. ${ }^{12,13}$ HIVAN frequently accompanies interstitial inflammation of the kidney, ${ }^{14-17}$ but the lack of pathognomonic findings in glomeruli in the present case made HIVAN unlikely. The lack of other glomerular changes such as podocyte hypertrophy and hyperplasia also contributed to excluding the diagnosis of HIVAN.

The pathogenesis of HIV-associated renal diseases, including HIVAN, has been thoroughly investigated, and the majority of current knowledge was gained from studies using animal models. HIV-1 can infect renal epithelial cells through infected CD4+ lymphocytes, and viral proteins such as Nef and Vpr may have a synergistic role in inducing podocyte dysfunction. This also leads to renal tubular epithelial cell apoptosis and tubulointerstitial inflammation, which results in one of unique histopathological changes of HIVAN. ${ }^{15,18,19}$ Through survey of the literature, we were unable to find studies on the pathogenesis of interstitial nephritis associated with HIV. Whether similar pathophysiological observations related to tubulointerstitial inflammation observed in patients with HIVAN applies to our case remains unknown.

The optimal therapy for HIV-associated interstitial nephritis is unknown, ${ }^{4}$ but ART is likely to be effective, as shown in the present case. An early study suggested that corticosteroids may be beneficial for improving the inflammatory lesions of HIVAN, ${ }^{20}$ but this treatment regimen is not commonly prescribed in the era of ART. Additionally, we cannot confirm that the application of corticosteroids would be beneficial for HIV-associated pure interstitial nephritis.

The exact incidence and morbidity of interstitial nephritis caused by HIV are unknown. Physicians should be aware of the possibility, and kidney biopsies should be performed for differential diagnosis of interstitial nephritis.

\section{Conclusion}

We identified interstitial nephritis without glomerular lesions in a treatment-naive HIV-infected patient, which was considered to be a complication of HIV infection. To our knowledge, the occurrence of interstitial nephritis in HIV-infected patients without other etiologies is rare, given the lack of similar reports. The findings presented herein are rare and should be further investigated to understand the potential role of interstitial nephritis on the prognosis of HIV infection.

\section{Author contributions}

All authors contributed toward data analysis, drafting and critically revising the paper and agree to be accountable for all aspects of the work.

\section{Disclosure}

The authors report no conflicts of interest in this work.

\section{References}

1. Praga M, González E. Acute interstitial nephritis. Kidney Int. 2010; 77(11):956-961.

2. Cohen SD, Chawla LS, Kimmel PL. Acute kidney injury in patients with human immunodeficiency virus infection. Curr Opin Crit Care. 2008;14(6):647-653.

3. Hartle PM, Carlo ME, Dwyer JP, Fogo AB. AKI in an HIV patient. $J$ Am Soc Nephrol. 2013;24(8):1204-1208.

4. Berliner AR, Fine DM, Lucas GM, et al. Observations on a cohort of HIV-infected patients undergoing native kidney biopsy. Am J Nephrol. 2008;28(3):478-486.

5. Wyatt CM, Morgello S, Katz-Malamed R, et al. The spectrum of kidney disease in patients with AIDS in the era of antiretroviral therapy. Kidney Int. 2009;75(4):428-434.

6. Szczech LA, Gupta SK, Habash R, et al. The clinical epidemiology and course of the spectrum of renal diseases associated with HIV infection. Kidney Int. 2004;66(3):1145-1152.

7. Nochy D, Glotz D, Dosquet P, et al. Renal disease associated with HIV infection: a multicentric study of 60 patients from Paris hospitals. Nephrol Dial Transplant. 1993;8(1):11-19.

8. Zaidan M, Lescure FX, Brochériou I, et al. Tubulointerstitial nephropathies in HIV-infected patients over the past 15 years: a clinico-pathological study. Clin J Am Soc Nephrol. 2013;8(6):930-938.

9. Parkhie SM, Fine DM, Lucas GM, Atta MG. Characteristics of patients with HIV and biopsy-proven acute interstitial nephritis. Clin J Am Soc Nephrol. 2010;5(5):798-804.

10. Basu D, Williams FM, Ahn CW, Reveille JD. Changing spectrum of the diffuse infiltrative lymphocytosis syndrome. Arthritis Rheum. 2006;55(3):466-472.

11. Feller L, White JP, Bouckaert M, Muthuphei MN. Diffuse infiltrative CD8+ lymphocytosis syndrome: review of the literature and report of a case. $S A D J .2007 ; 62(7): 314-317$.

12. Szczech LA. Tackling the unknowns in HIV-related kidney diseases. $N$ Engl J Med. 2010;363(21):2058-2059.

13. Cohen SD, Kimmel PL. Renal biopsy is necessary for the diagnosis of HIV- associated renal diseases. Nat Clin Prac. 2009;5(1): $22-23$.

14. Wearne N, Swanepoel CR, Boulle A, Duffield MS, Rayner BL. The spectrum of renal histologies seen in HIV with outcomes, prognostic indicators and clinical correlations. Nephrol Dial Transplant. 2012;27(11): $4109-4118$.

15. Kimmel PL, Barisoni L, Kopp JB. Pathogenesis and treatment of HIVassociated renal diseases: lessons from clinical and animal studies, molecular pathologic correlations, and genetic investigations. Ann Intern Med. 2003;139(3):214-226. 
16. Laurinavicius A, Hurwitz S, Rennke HG. Collapsing glomerulopathy in HIV and non-HIV patients: a clinicopathological and follow-up study. Kidney Int. 1999;56(6):2203-2213.

17. Abbott KC, Hypolite I, Welch PG, Agodoa LY. Human immunodeficiency virus/acquired immunodeficiency syndrome-associated nephropathy at end-stage renal disease in the United States: patient characteristics and survival in the pre highly active antiretroviral therapy era. J Nephrol. 2001;14(5):377-383.
18. Hanna Z, Kay DG, Rebai N, Guimond A, Jothy S, Jolicoeur P. Nef harbors a major determinant of pathogenicity for an AIDS-like disease induced by HIV-1 in transgenic mice. Cell. 1998;95(2):163-175.

19. Medapalli RK, He JC, Klotman PE. HIV-associated nephropathy: pathogenesis. Curr Opin Nephrol Hypertens. 2011;20(3):306-311.

20. Smith MC, Austen JL, Carey JT, et al. Prednisone improves renal function and proteinuria in human immunodeficiency virus-associated nephropathy. Am J Med. 1996;101(1):41-48.

\section{Publish your work in this journal}

The International Journal of General Medicine is an international, peer-reviewed open-access journal that focuses on general and internal medicine, pathogenesis, epidemiology, diagnosis, monitoring and treatment protocols. The journal is characterized by the rapid reporting of reviews, original research and clinical studies across all disease areas.
The manuscript management system is completely online and includes a very quick and fair peer-review system, which is all easy to use. Visit $\mathrm{http}: / / \mathrm{www}$.dovepress.com/testimonials.php to read real quotes from published authors.

Submit your manuscript here: https://www.dovepress.com/international-journal-of-general-medicine-journal 